\title{
Flow Directions and Paleomagnetic Study of Rocks from the Azufre Volcano, Argentina
}

\author{
E. Cañón-Tapia, E. Herrero-Bervera, and G. P. L. Walker \\ SOEST-HIG, University of Hawaii, Honolulu, HI 96822, U.S.A.
}

(Received January 11, 1993; Revised May 25, 1993; Accepted August 5, 1993)

\begin{abstract}
Determination of the stable direction of magnetization was made on eight lava flows from the Azufre volcano, Southern Volcanic Zone of the Andes. From these eight paleomagnetic sites, only six independent samples of the geomagnetic field were identified. Combination of these with results of a work made by CREER and VALENCIO (1969) allowed a better determination of a geomagnetic pole for the Bruhnes chron in this region of the Andes than that previously calculated. The coordinates of the new pole are $87^{\circ} \mathrm{N}, 236^{\circ} \mathrm{E}$, and have an $\alpha_{95}$ region of confidence of $12^{\circ}$. Statistical comparison of directions of magnetization of groups of flows was used 1) to test the hypothesis of rapid extrusion of flows, and 2) to constrain the age of the lavas sampled in this work to more than 0.4 my. Finally, the utility of the anisotropy of magnetic susceptibility measurements on the determination of flow direction of lava flows was established despite the great scatter on the observations of multiple samples from the same unit. Criteria to determine the size of the region of confidence around the mean maximum susceptibility in order to accept or reject results were developed in analogy with those used in paleomagnetic studies.
\end{abstract}

\section{Introduction}

Although the main purpose of paleomagnetism is to study the behavior of the Earth's magnetic field in the past, paleomagnetic information can also be used to constrain important volcanological aspects. In this paper, paleomagnetic results from eight, randomly selected, lava flows from the Azufre volcano, Andean Cordillera $\left(35.25^{\circ} \mathrm{S}, 289.5^{\circ} \mathrm{E}\right)$ are reported. Due to the interbedding of lavas from two volcanoes (Azufre and Planchón, Fig. 1(a)), anisotropy of magnetic susceptibility (AMS) measurements were made to determine flow directions of the sampled lavas. Additionally, magnetic correlation techniques were used 1) to test the hypothesis of rapid extrusion of lava flows, and 2) to constrain the age of the Azufre lavas by comparing their directions of magnetization with that obtained from a group of lavas of the Mendoza and Neuquén provinces, Argentina, which have been previously dated by radiometric methods.

\section{Geological Setting and Sampling Procedures}

The site of study is located in a transition zone between andesite volcanoes to the north and basaltdacite volcanoes to the south (TORMEY et al., 1989). Overlapping volcanic products from three volcanoes: Planchón, Peteroa and Azufre, aligned from north to south (Fig. 1(a)) have formed a complex structure. TORMEY et al. (1989) estimated that the age of the oldest volcano of the complex, the Azufre, is less than $0.55 \mathrm{My}$. They also concluded that the Planchón volcano initiated its activity after approximately $75 \%$ of the Azufre lavas had been erupted, and inferred that the intervals between extrusion of the Azufre lavas were short because of the lack of sedimentary deposits between flows.

Cores from eight lava flows were obtained using two gasoline powered drills. Orientation of samples was made with magnetic compass, and additionally in the North group a solar compass was used. The mean difference in the magnetic and solar orientation was $2^{\circ}$ after correction for the local declination $\left(10^{\circ}\right)$. The division of the eight flows in the hereafter called North and South groups, was made according with their location on the complex (Fig. 1(a)). Each group is formed by four individual lava flows, or flow 

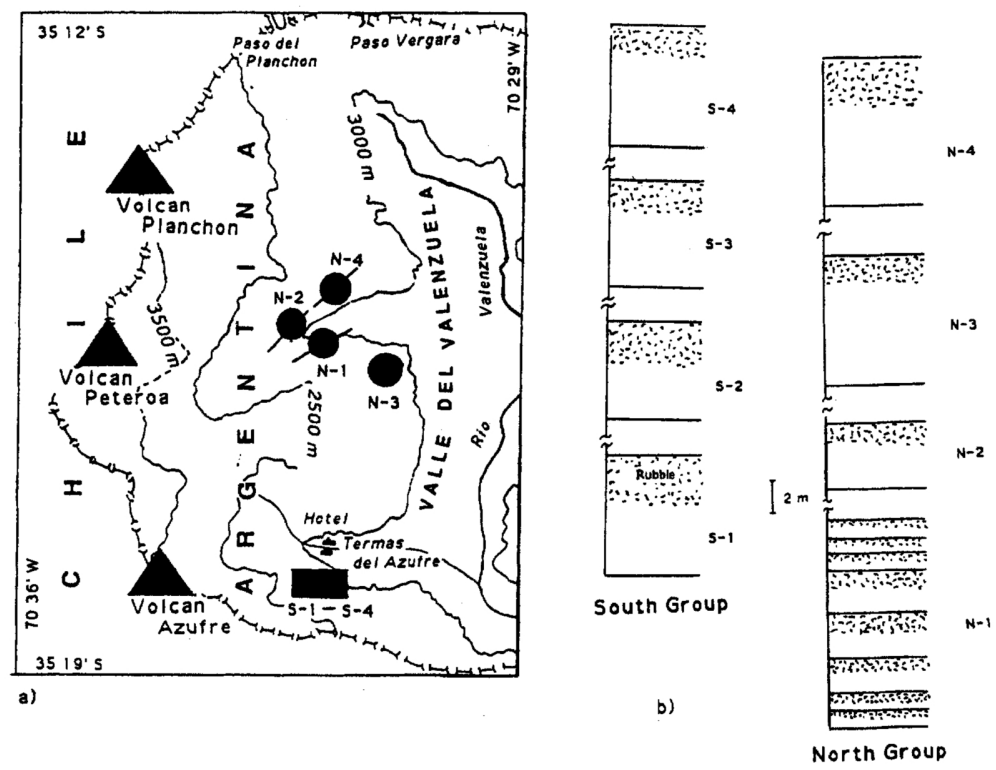

Fig. 1. (a) Location of the area of study of this work. Lines on three flows from the North group indicate the flow direction inferred from AMS measurements. (b) Schematic stratigraphic sequence of South and North group flows.

units; the N-1 flow is a compound flow, i.e., it is formed of several flow units, five of which were sampled. Numerous landslides covering most of the flanks of the volcanoes, as well as a sheet of ashes deposited during a period of activity of Peteroa volcano that was coming to an end during our visit to the complex, precluded a strict control on the stratigraphy of the sampled flows. Therefore, only schematic stratigraphic sections of both North and South groups are shown in Fig. 1(b). A minimum of 5 cores, subsequently cut in two specimens, were drilled from each flow of the South group while in the North the minimum number of cores was 15 .

\section{Paleomagnetic Results}

\subsection{Previous work}

Preliminary measurements on some of the rock samples, made on a Schonsted spinner magnetometer, showed a large increase in the intensity of the remanence without significant change in its direction after demagnetization at $2.5 \mathrm{mT}$. These results were interpreted as indicators that a partial self-reversal had taken place in the studied rocks (CAÑON-TAPIA, 1991). However, the sudden character of the increase in intensity, the large value of the ratio $J_{2.5} / J_{\mathrm{NRM}}(\sim 1.5-2.0)$, and the shape of the demagnetization curves, all raised the question of whether the experimental results were accurately reflecting an actual phenomenon. To eliminate the possibility of accidental magnetic contamination of the samples by a magnetic field during the demagnetization process, the remaining samples were measured on a cryogenic magnetometer which is inside the same field-free space as the three-axis tumbler and oven used for alternating field (AF) and thermal demagnetization, respectively. The field-free space is provided by the mu-metal room of the Paleomagnetic Laboratory at the University of Hawaii. Results from most of these specimens (Fig. 2) also show an increment in the initial intensity of magnetization with the first steps of demagnetization, but the ratio $J_{\mathrm{MAX}} / J_{0}$ is considerably lower $(\sim 1.05-1.1)$ which invalidates the argument of partial self-reversal reported before (CAÑÓN-TAPIA, 1991). It was later established that only an error on the intensity of the remanence, produced by the failure of the spinner magnetometer to record changes in the distance between the sensor and the sample, was the cause of the large increase in intensity, leaving unaffected the direction 

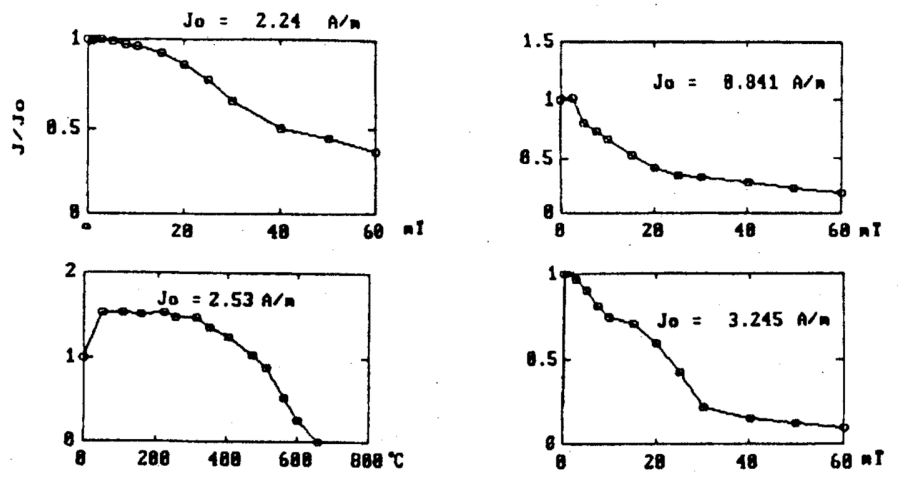

a)
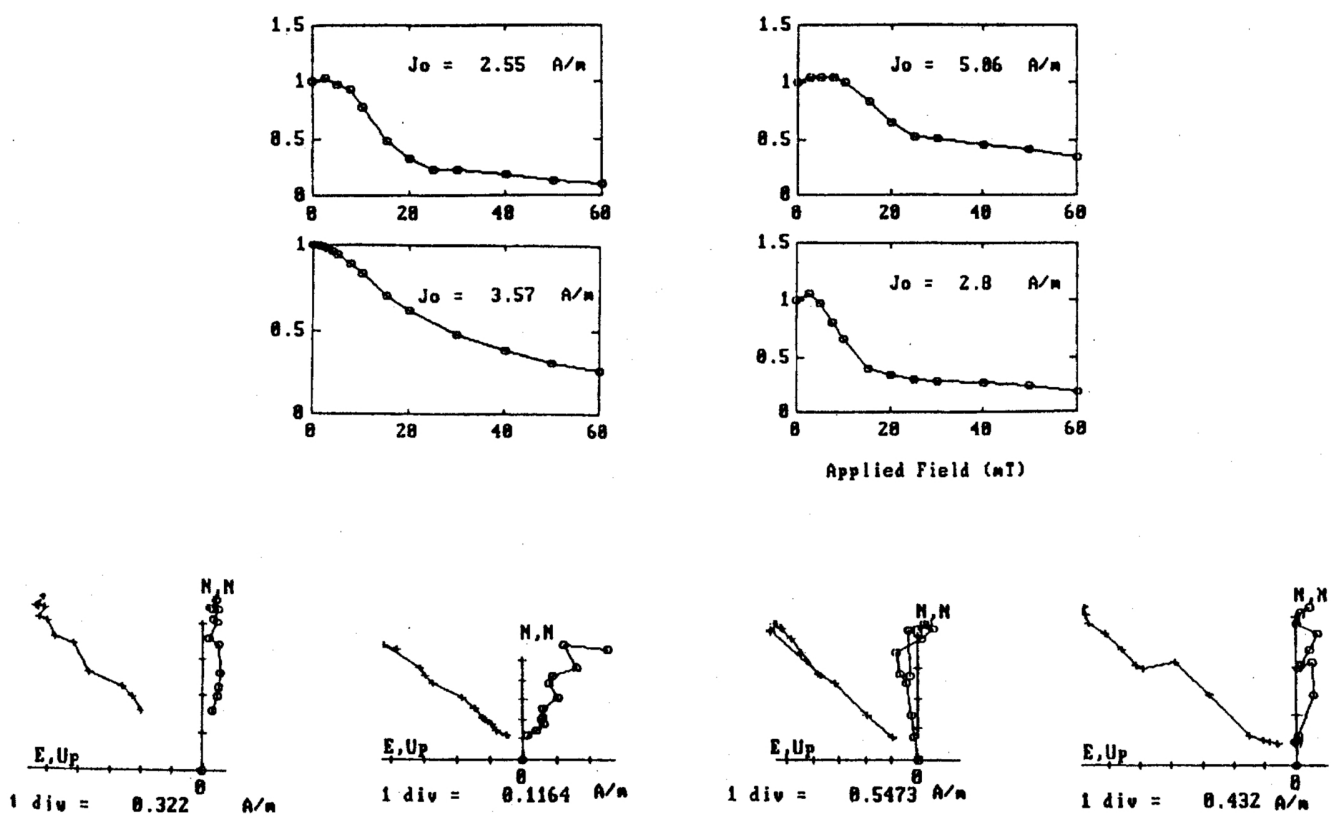

b)
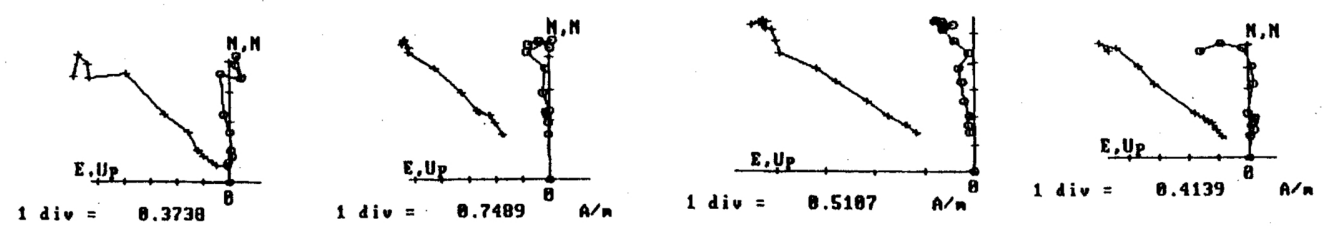

Fig. 2. Demagnetization of selected specimens of the Azufre volcano flows. (a) Normalized intensity of the remanence against demagnetizing field (note that one flow of the North group, N-3, was thermally demagnetized). (b) ZIJDERVELD (1967) diagrams (solid symbols: vertical projection; circles: horizontal projection). 

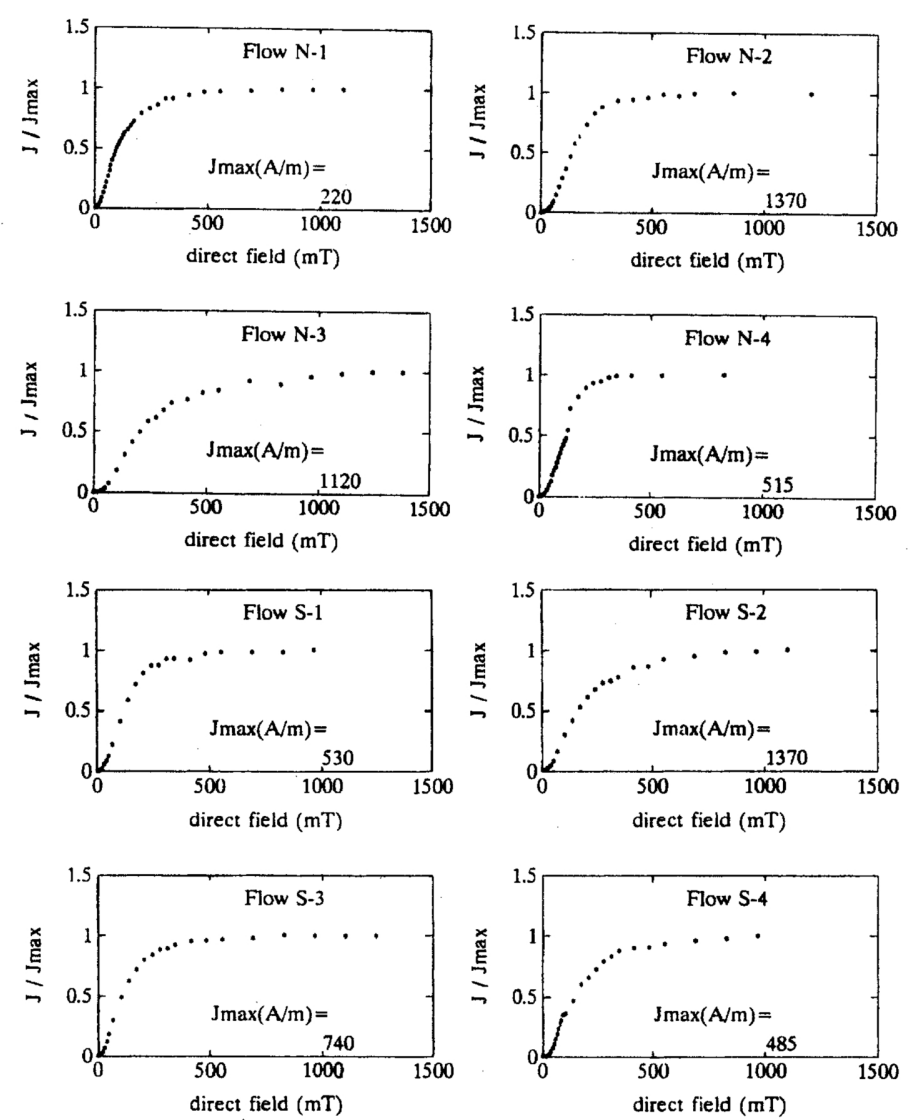

Fig. 3. Aquisition curves of IRM of selected samples from the Azufre volcano.

of the remanence. However, in the calculation of the direction of the characteristic remanent magnetization (ChRM) reported below, most of the samples measured in the spinner magnetometer were discarded, and only those for which the intensity of the remanence decreased steadily were included.

Isothermal remanent magnetization (IRM) acquisition curves (Fig. 3) reflect the presence of two mineral phases, one of low and other of higher coercivity in most of the studied samples. The effects of the higher coercivity mineral are appreciably larger in the N-3 flow. Thermal demagnetization of selected samples from each flow yield similar results to those of AF demagnetization in terms of the stability of the direction of the remanence, and therefore, the later method was used for simplicity in the bulk of the sample collection, with exception of the N-3 flow, where AF barely decreased the intensity of the remanence, in accordance with the inferred predominance of the high coercivity phase from IRM curves.

\subsection{NRM and ChRM}

Numerical values of the mean directions of the natural remanent magnetization (NRM) and of the characteristic remanent magnetization (ChRM) are listed in Table 1 together with their respective precision parameter $k$ and angle of the $95 \%$ cone of confidence (FISHER, 1953). Equal area projections of the $\alpha_{95}$ intervals around the average NRM directions are shown in Fig. 4(a). The direction of the ChRM (Fig. 4(b)) were determined using the anchored origin principal component analysis (PCA) technique (KIRSCHVINK, 1980) in all the specimens for which the intensity of the NRM had at least halved its initial value. Also, specimens with a value of the maximum angular deviation (MAD) larger than $6^{\circ}$ were not 
Table 1. Paleomagnetic results from Azufre volcanic rocks. NRM = natural remanent magnetization; ChRM = characteristic remanent magnetization; $\mathrm{S} / \mathrm{N}=$ samples collected/number of specimens used in the calculation of ChRM; $D=$ declination of magnetization measured from the North, in degrees; $I=$ inclination from the horizontal, in degrees; $\alpha_{95}=95 \%$ circle of confidence; $k=$ fisher parameter. Flows S-3 with S- 4 and S-2 with N-3 were combined to yield the two directions listed at the bottom of the table. The directions of the ChRM used in the calculation of the VGP of the Azufre lavas are marked with an asterisk.

\begin{tabular}{|c|c|c|c|c|c|c|c|c|c|}
\hline \multirow[t]{2}{*}{ Flow } & \multirow[t]{2}{*}{$\mathrm{S} / \mathrm{N}$} & \multicolumn{4}{|c|}{ NRM } & \multicolumn{4}{|c|}{ ChRM } \\
\hline & & $D$ & $I$ & $\alpha_{95}$ & $k$ & $D$ & $I$ & $\alpha_{95}$ & $\dot{k}$ \\
\hline S-4 & $7 / 7$ & 340.1 & -42.3 & 16.4 & 8.7 & 359.0 & -42.7 & 4.0 & 223.1 \\
\hline S-3 & $6 / 7$ & 357.1 & -44.8 & 4.3 & 201.1 & 355.0 & -43.7 & 3.3 & 334.9 \\
\hline S-2 & $5 / 9$ & 358.8 & -50.2 & 4.9 & 112.3 & 356.5 & -49.8 & 4.1 & 157.2 \\
\hline$* \mathrm{~S}-1$ & $7 / 13$ & 0.4 & -60.0 & 5.4 & 60.8 & 354.9 & -54.6 & 3.7 & 123.9 \\
\hline${ }^{*} \mathrm{~N}-4$ & $14 / 12$ & 12.4 & -62.5 & 4.2 & 90.7 & 13.8 & -63.6 & 3.8 & 128.7 \\
\hline N-3 & $11 / 11$ & 359.3 & -50.3 & 4.1 & 125.1 & 359.5 & -47.4 & 2.4 & 353.6 \\
\hline${ }^{*} \mathrm{~N}-2$ & $8 / 6$ & 353.7 & -39.9 & 36.1 & 3.7 & 4.6 & -34.3 & 7.2 & 87.3 \\
\hline$* \mathrm{~N}-1$ & $38 / 38$ & 9.7 & -49.4 & 2.3 & 198.0 & 9.5 & -50.5 & 1.3 & 308.3 \\
\hline${ }^{*} \mathrm{~S}-3+\mathrm{S}-4$ & $13 / 14$ & & & & & 357.0 & -43.2 & 2.5 & 260.6 \\
\hline${ }^{*} \mathrm{~S}-2+\mathrm{N}-3$ & $16 / 20$ & & & & & 358.2 & -48.5 & 2.2 & 220.0 \\
\hline
\end{tabular}

included in further calculations (typical MAD values were between $1^{\circ}$ and $4^{\circ}$ ). Note that because the PCA method gives more weight to the information contained in those points that are farther from the origin, and due to the directional stability observed during thermal demagnetization of selected samples, not much would be gained in extending the demagnetization procedures to further decrease the intensity of the remanence.

The resulting directions of the ChRM shown in Fig. 4(b), generally shallower than the expected direction of magnetization of the locality assuming a coaxial dipolar model of the geomagnetic field, show an overlapping of the regions of confidence of some of the flows, indicating that some of these directions could not be considered as independent samples of the geomagnetic field. Therefore, all the specimens of flows S-2 and S-3 as well as those from flows S-4 and N-3 were combined in a single site, yielding the two additional ChRM directions reported in Table 1. The resulting six independent samples of the geomagnetic field are shown in Fig. 4(c).

The mean virtual geomagnetic pole (VGP) from the six independent samples of the geomagnetic field of the Azufre lavas is compared with the VGP position obtained by CREER and VALENCIO (1969) from several flows of the Bruhnes Chron in Table 2(a) and Fig. 5(a); clearly, both VGPs are undistinguishable at a $95 \%$ confidence level. This result could suggest at a first sight the possibility that despite the small number of sites sampled in this work the effects of the secular variation had been somehow averaged out. However, a closer look to the data reported by CREER and VALENCIO (1969) revealed that their VGP position had been calculated using the directions of magnetization of only six sites, four of which were undistinguishable at a $95 \%$ confidence level and which ought to be combined into one average direction, reducing then to three their number of independent samples of the geomagnetic field during the Bruhnes chron (these are the corresponding to their basalt V, VI and VII groups). Thus, we decided to add these three paleomagnetic sites to our results from the Azufre to form a single set of nine independent samples of the geomagnetic field that allow a better determination of a paleomagnetic pole for the Bruhnes chron in this part of South America, but unfortunately, two of the directions obtained by CREER and VALENCIO (1969) were undistinguishable from two of the six Azufre sites, and therefore, after averaging them, the number of independent sites was of only seven (Table 2(b)). A mean VGP was calculated from the seven 


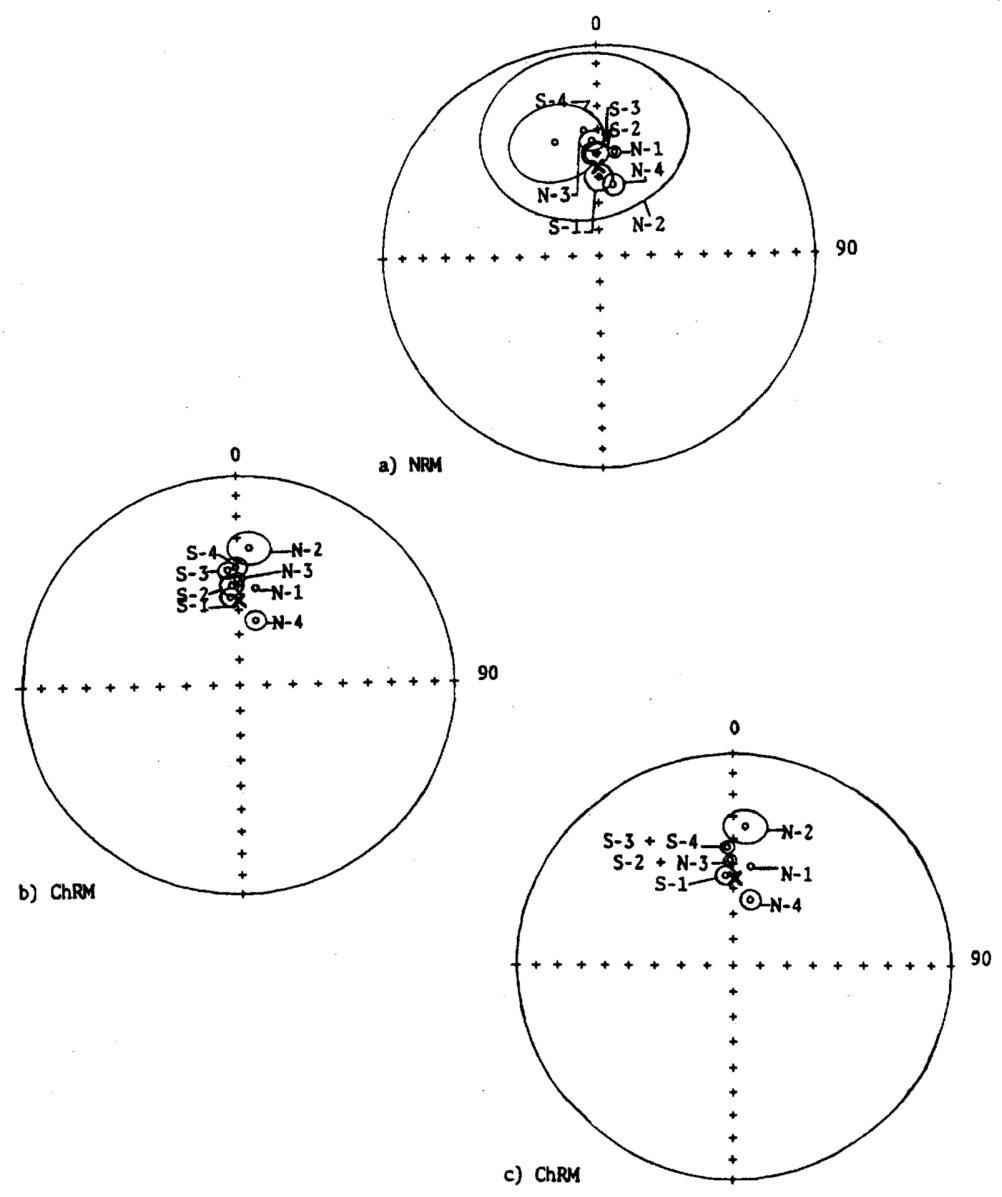

Fig. 4. Equal area projections (upper hemisphere) of (a) NRM, (b) ChRM directions of the eight flows sampled, and (c) the six independent samples of the geomagnetic field.
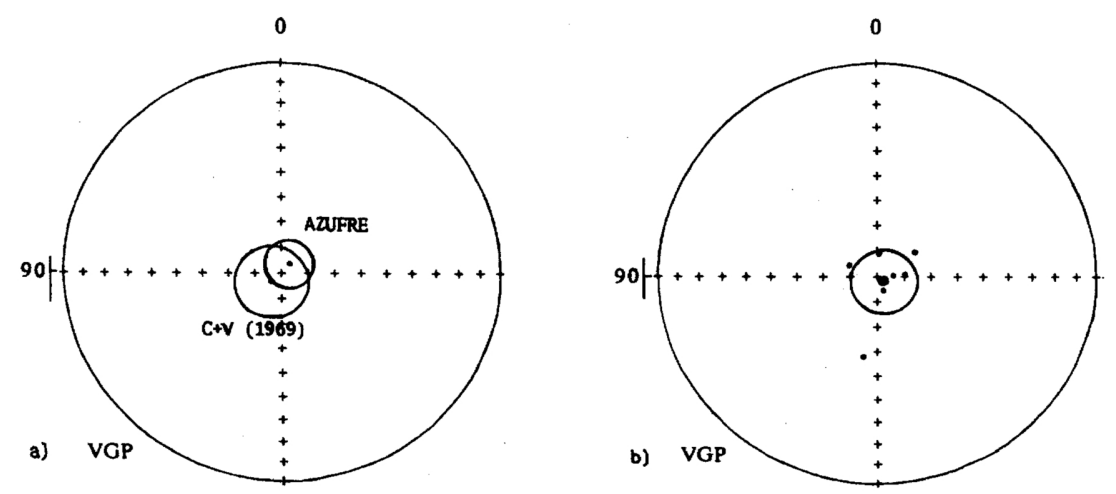

Fig. 5. Virtual Geomagnetic Poles from (a) the Azufre volcano and a group of flows reported by CREER and VALENCIO (1969), and (b) the seven independent samples of the geomagnetic field obtained by combining the previous work and Azufre flows. 
Table 2(a). Site coordinates and VGPs location derived 1) from this work, 2) from CREER and VALENCIO (1969), and 3) combining both sets of data.

\begin{tabular}{|c|c|c|c|c|c|}
\hline & \multicolumn{2}{|c|}{ Site coordinates } & \multicolumn{3}{|c|}{ VGP coordinates } \\
\hline & Lat $\left({ }^{\circ} \mathrm{S}\right)$ & Long $\left({ }^{\circ} \mathrm{E}\right)$ & Lat $\left({ }^{\circ} \mathrm{N}\right)$ & Long $\left({ }^{\circ} \mathrm{E}\right)$ & $\alpha_{95}$ \\
\hline 1) & 35.25 & 289.5 & 85.2 & 318.1 & 9.1 \\
\hline 2) & 35 & 311 & 85 & 131 & 14.0 \\
\hline 3) & & & 86.9 & 236.5 & 12.5 \\
\hline
\end{tabular}

Table 2(b). Directions of magnetization of the seven independent samples of the geomagnetic field used to calculate the pole of the last line of Table 2(a). BV, BVI and BVII refer to the basalt V, VI and VII of CREER and VALENCIO (1969), respectively.

\begin{tabular}{lrcr}
\hline \multicolumn{1}{c}{ Flow(s) } & Declination & Inclination & $\alpha_{95}$ \\
\hline N-1 & 9.5 & -50.5 & 1.3 \\
N-2 & 4.6 & -34.3 & 7.2 \\
N-4 + S-3 & 357.0 & -43.2 & 2.5 \\
S-2 + S-3 & 358.2 & -48.5 & 2.2 \\
S-1 + BVI & 352.9 & -54.3 & 5.1 \\
N-4 + BV & 10.6 & -61.7 & 10.2 \\
BVII & 7.7 & -59.8 & 7.7 \\
\hline
\end{tabular}

VGPs associated with those seven sites which is shown in Fig. 5(b) and on the last line of Table 2(a). The dispersion associated with these seven VGPs $\left(16^{\circ}\right)$ is in good agreement with the predicted value for the $35^{\circ}$ of latitude in a world wide scale due to secular variation (e.g. MCELHINNY and MERRILL, 1975; BUTLER, 1992), and therefore, even though the number of independent sites used was smaller than usually required, the average VGP reported here seems to be a better result than that of either the work of CREER and VALENCIO (1969) or the Azufre flows if considered independently from each other.

\section{Rate of Extrusion and Age of the Flows}

BOGUE and COE (1981) developed a rigorous statistical technique that allows the evaluation of the probability that groups of flows had been erupted during a short period of time when compared with the secular variation of a given place and time. In this section we used this technique to compare the average directions of magnetization of the North and South groups to each other as well as with the direction of magnetization of the basalt $V$ group of CREER and VALENCIO (1969). The value of K reflecting the effects of the secular variation obtained from the compilation of MCELHINNY and MERRILL (1975) is about 38 for a $35^{\circ}$ latitude. However, a lower value of 30 was used in the following calculations leading to a more conservative estimate of the reliability of the correlations by assuming a larger variation of the field direction than the latitudinal average for the last $5 \mathrm{my}$. The necessary angular distances between the mean directions of the three groups to be correlated to each other (column e) as well as between each group and the expected direction of magnetization assuming a coaxial dipolar model of the geomagnetic field (column d) are listed in Table 3. The likelihood associated with the hypothesis that pairs of groups of flows had been erupted at different times yielding the observed directions merely by coincidence shown in column f of Table 3 was calculated using the probability curves provided in the appendix of BoGUE and COE (1981).

In order to estimate the probability that the observed directions were produced during the same period of time, or geomagnetic instant, the errors that may have affected the mean directions need to be evaluated. 
Table 3. Values of (a) the mean declination, (b) mean inclination, (c) angular dispersion and (d) angular distance of the mean direction of magnetization with the expected field on the locality $\left(0^{\circ},-55^{\circ}\right)$ of the North group (first line), South group (second line) and basalt $\mathrm{V}$ group (third line). Columns (e) to $(\mathrm{g})$ are the angular distance, the random sampling probability and the simultaneous sampling probability, respectively; results of the comparison of the North and South groups, South and Basalt V and, North and Basalt V are shown in the first, second and third lines, respectively.

\begin{tabular}{lrrrrrrr}
\hline & (a) & (b) & (c) & (d) & (e) & (f) & (g) \\
\hline N-1 to N-4 & 6.1 & -49.1 & 12.6 & 7.0 & 6.5 & .145 & .799 \\
S-1 to S-4 & 356.4 & -47.7 & 5.7 & 7.6 & 13.8 & .520 & .087 \\
Basalt V & 7.7 & -59.8 & 6.7 & 6.4 & 10.8 & .340 & .562 \\
\hline
\end{tabular}

We used the value of the between-flow angular dispersion in each group of flows as a measure of this characteristic error, mainly because no signs of change on the original position of the Azufre flows was observed, and there was no way to estimate the tectonic error of the basalt $\mathrm{V}$ group from the published information. This approximation was justified because, as pointed out by BOGUE and COE (1981), the systematic error due to field anomalies is usually small enough as to have a negligible effect on the calculations, and the used angular dispersion is larger than the average angular dispersion obtained as the sum of the squares of the angular dispersions of each flow divided by the total number of flows in each group. The resultant likelihood associated with the simultaneous hypothesis is given in the column $\mathrm{g}$ of Table 3. It can be observed that the correlation of North and South groups have a larger ratio simultaneous/ random hypothesis than any of the other two correlations; moreover, in the case of the correlation of the South-basalt $\mathrm{V}$ groups it is the random hypothesis which is clearly more favored. The rather ambiguous result obtained for the correlation North-basalt $\mathrm{V}$ groups can be partly due to the coincidence in the directions of magnetization of the N-4 flow and the mean direction of the basalt $\mathrm{V}$ group.

Several interesting conclusions can be drawn from the correlations made. First, the hypothesis of a very rapid extrusion of lavas from the Azufre volcano mentioned earlier has found support from the results of the correlation of directions of magnetization of the North and South groups; note that the stratigraphic position of the flows of the North group extends from near the base of the exposed lava pile to close to its top, while the flows in the South group are concentrated somewhere in the middle of the total height of the volcanic building. Second, the coincidence of the directions of one flow in the North side of the Azufre and the mean direction of the basalt $\mathrm{V}$ flow suggests the possibility that this particular flow had been erupted almost at the same time than the flows forming the basalt $\mathrm{V}$ group, which has been radiometrically dated by VALENCIO et al. (1970) in $0.5 \pm .3 \mathrm{Ma}$. Furthermore, considering the position of the N-4 flow in the lava pile of the Azufre, it seems reasonable to suggest that the age of this volcano should not exceed 0.4 Ma on the average, or at least, that the Azufre volcano is older than the basalt V group.

\section{AMS Measurements}

Up to this point it was implicitly assumed that all the flows were part of the Azufre volcano, although due to their location, three flows of the North group could be not Azufre but Planchón flows. Because of the chemical and mineralogical similarities between the lavas from both volcanoes (TORMEY et al., 1989) AMS was used to infer their possible source vent. AMS was measured on a Kappabridge KLY-2 instrument, and statistical analyses were made using both an updated version of the program of LIENERT (1991) and the program used in CONSTABLE and TAUXE (1990).

\subsection{Background}

It has been commonly accepted that the preferred orientation of magnetic grains, controlled by the flow of magma, determines the AMS of igneous rocks (see HROUDA, 1982; BORRADAILE, 1988; JACKSON and TAUXE, 1991; for recent reviews) although HARGRAVES et al. (1991) pointed out that the preferred 
orientation of magnetic grains is not necessarily the cause of AMS in pristine igneous rocks. However, their experimental results showed that AMS measurements provide a direct record of fluid-dynamic histories of igneous rocks because they are a direct, or indirect, reflection of the preexisting silicate fabric, therefore, supporting the use of this technique as an indicator of the flow direction in igneous rocks in addition to the empirical previous observations made in dikes (e.g., KHAN, 1962; KNIGHT and WALKER, 1988; ERNST and BARAGAR, 1992; STAUDIGEL et al., 1992) and pyroclastic flows (e.g., ELLWOOD, 1982; KNIGHT et al., 1986).

However, AMS results in lava flows have been somewhat contradictory, for in one hand KHAN (1962) and SYMONS (1975) found a large scatter on the AMS directions and little or no relationship at all between their means and the flow directions determined from the geological evidence and on the other, Kolofikova (1976, referred to in HROUdA, 1982), and CAÑÓN-TAPIA et al. (1993a, b) have found that the maximum axis of susceptibility is very close to the mean flow direction of some flow units. The observed scatter on the AMS directions can be attributed to the effects of convection patterns or of local turbulence within the flow boundaries (KHAN, 1962) and may certainly obscure the results, although it must be noted that the method used to calculate the mean direction of the principal axis of the AMS tensor, let alone the determination of the regions of confidence around these means, has not always take into account the tensor nature of the magnetic susceptibility. Another important factor can be the distribution of the samples: the best results are obtained provided the middle parts of the flow and not the frontal section are sampled (KOLOFIKOVA, 1976), and finally, the distribution of samples with height in the flow, and the flow thickness can be also very important (CAÑóN-TAPIA et al., 1993). Therefore, it seems reasonable to assume, based in the previous results, that if the mean directions of the axis of maximum magnetic susceptibility are found to be significantly well constrained, and the samples used in the measurement of AMS are distributed along the width of the flow, the direction of the axis of maximum susceptibility will closely approach the direction of flow of the studied lavas. Fortunately, although it was not our primary purpose to establish the utility of AMS as indicator of flow direction in lavas, sample distribution fulfilled the necessary requirements stated above in all the North group flows, while in the South group sample collection phocused on the middle parts of the flows, affecting to some extent the obtained results (see below).

Two main methods to estimate the sizes of the intervals of confidence around the mean directions have been proposed; one using a linear perturbation analysis (HEXT, 1963; JELINEK, 1978) and the other, using a Monte Carlo re-sampling of the data to generate the statistical distributions (of the type of the FB5 distribution of KENT, 1982) for the confidence intervals (CONSTABLE and TAUXE, 1990). In the first case, the regions of confidence are the regions where the $5 \%$ of the least probable positions of each of the principal directions have been eliminated (JELINEK, 1978), and though of approximate nature LIENERT (1991) concluded that the performance of Jelinek's method is extremely good except for a small underestimate of the confidence region size when the directions of the individual samples are almost randomly distributed. In the second case, the confidence regions were defined as to include $95 \%$ of the observations (CONSTABLE and TAUXE, 1990), and usually are of a larger size than those obtained using Jelinek's approach. However, it was found for the Azufre lavas that the regions of confidence around the mean maximum susceptibility using the bootstrap method were smaller than those using the hypothesis of a normal distribution of the data. In Figs. 6 and 7 only the latter type of regions of confidence are shown for clarity but the corresponding dimensions of both types of confidence regions are compared numerically in each case.

Once that the interval of confidence has been estimated, it is necessary to decide whether the results are significant to the determination of the flow direction. TAUXE et al. (1990) suggested a scheme of classification of the shapes, as well as a possible statistical treatment for the variations of the mean ellipsoid of anisotropy of each site, but, surprisingly, criteria relative to the size of the confidence regions have not been established anywhere before. Thus, the criteria that we adopted was established in analogy with those used in the determination of the mean directions of magnetization in paleomagnetic studies (see e.g., BUTLER, 1992), and with that previously suggested by KNIGHT and WALKER (1988), i.e., defining 


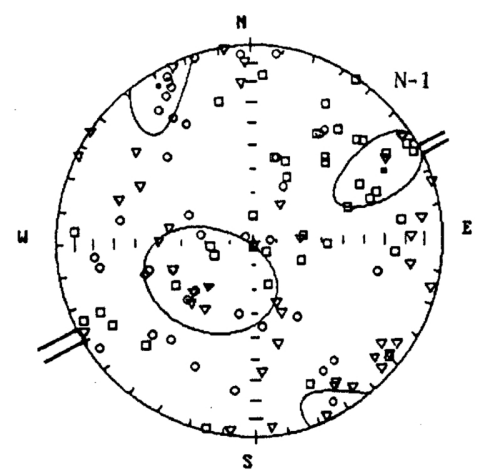

$D_{\max }=63.8 I \max =24.1 \pm 25: 10(25: 11)$

Dint $=228.7$ lint $=65.3 \pm 28: 22(34: 25)$

$D_{\min }=339.6 \operatorname{Imin}=5.4 \pm 25: 19(34: 10)$

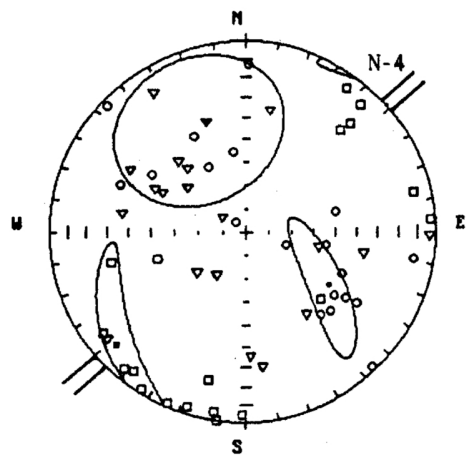

$D_{\max }=51.9 I \max =-16.5 \pm 34: 7 \quad(22: 14)$

Dint $=335.8$ lint $=39.1 \pm 35: 33 \quad(90: 22)$

$D_{\min }=393.9 \operatorname{Inin}=-46.2 \pm 34: 8 \quad(90: 14)$

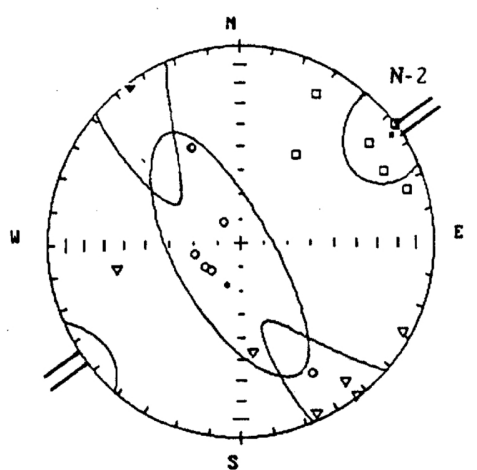

$D_{\max }=234.6 I_{\max }=-9.3 \pm 23: 14(16: 10)$

Dint $=324.2$ lint $=2.3 \pm 59: 13(90: 14)$

$D_{\min }=228.4 \operatorname{Im}$ in $=89.4 \pm 59: 21(90: 13)$

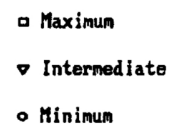

Fig. 6. Equal area projections of the AMS measurements from samples of the N-1, N-2 and N-4 flows. Numbers in parenthesis are the dimensions of the regions of confidence calculated using the bootstrap method.

sizes of the confidence regions for which the quality of the results are graded. However, a slight modification from these approach is necessary due to the differences in the geometry of the $\alpha_{95}$ and AMS intervals of confidence. We used the normalized area of the region of confidence, obtained by multiplying together the sine of each of its semiaxis (the length of each semiaxis is expressed in degrees and is analogous to the $\alpha_{95}$ parameter), as a measure of its size. Note that the area of the circle defined by an $\alpha_{95}$ $=90^{\circ}$, divided by the normalizing factor $\pi$, is equal to one in the unitary sphere. The following threshold values were defined: $<.03$ (excellent), $<.07$ (very good), $<.12$ (good), $<.18$ (moderate), $<.25$ (fair) and $>.25$ (poor), which are equivalent to an $\alpha_{95}$ of $10^{\circ}, 15^{\circ}, 20^{\circ}, 25^{\circ}$ and $30^{\circ}$, respectively (see KNIGHT and W ALKER (1988) and BUTLER (1992) for a discussion about the threshold values).

This scheme gives an objective means of evaluation of the size of confidence regions but, it must be noticed that one set of data could be considered as not reliable if one of the semiaxis of confidence is extremely large, despite the fact that the area may be below the limits of the category "good". This is the result of some girdle-like regions of confidence that can be found in the analysis of AMS data (STONE, 1967). Therefore, additional criteria mainly related with the orientation of the semiaxis of the regions of confidence, should be used to decide if the mean direction is geologically significant or not. 

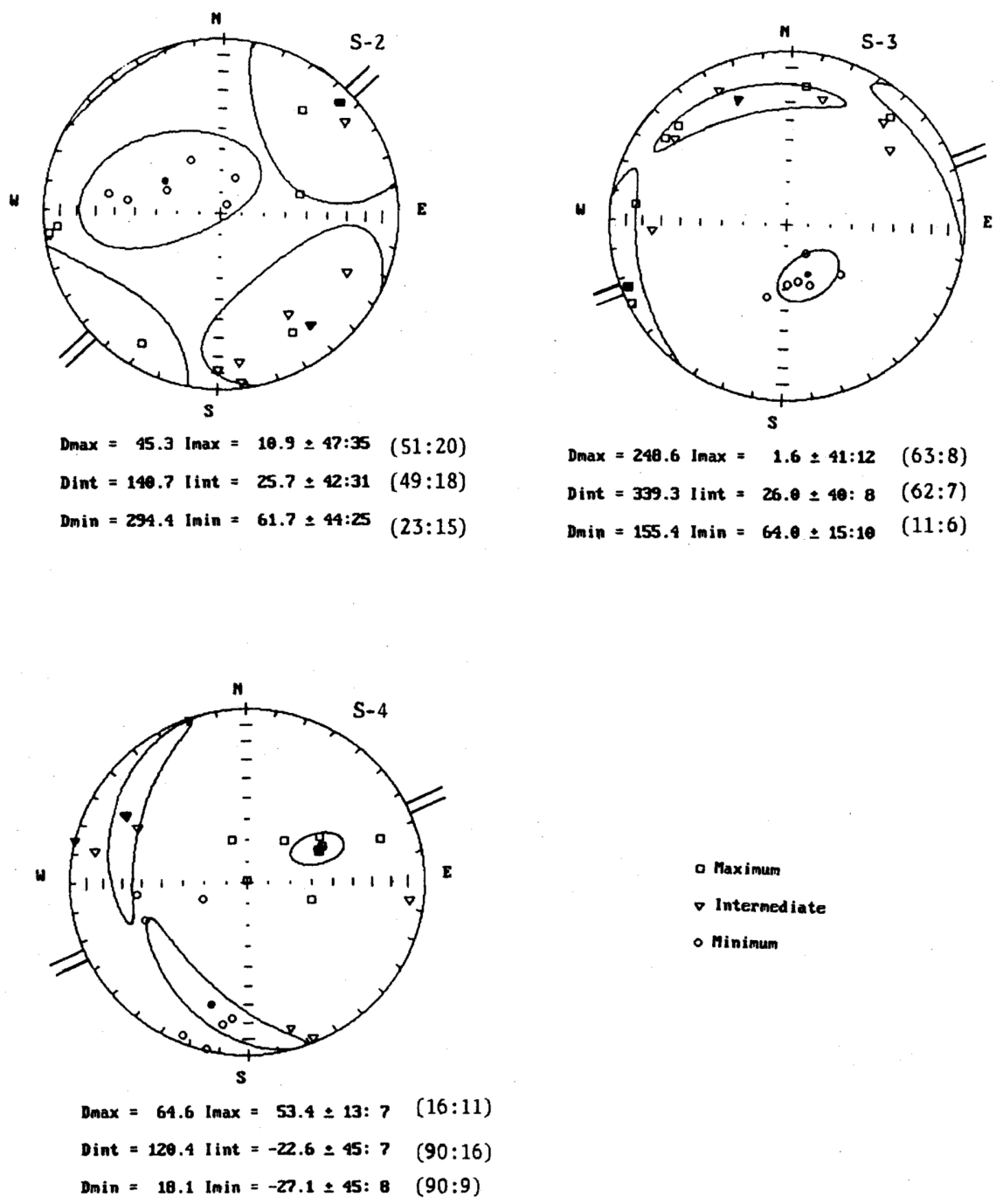

Fig. 7. Equal area projections of the AMS measurements from samples of the S-1, S-2 and S-3 flows.

\subsection{Results}

Results of AMS measurements of the three North group flows whose source was not clear are shown in Table 4(a) and Fig. 6. All the confidence intervals of the mean maximum susceptibilities have an area smaller than .12, and the orientation of the ellipses of confidence does not present a particular problem in any case. Therefore, the directions marked by the double lines in the equal area projections of Fig. 6 , were assumed to represent the direction of movement of the flows at the point of sampling. In all the three cases, the most likely vent of origin implied by the above directions is the Azufre and not the Planchón volcano (see lines in Fig. 1(a)).

AMS measurements were also used in three flows from the South group of this work (we had to exclude the fourth flow because of the lack of enough samples with the appropriate dimensions and shapes for reliable AMS measurements) to see wether the Azufre volcano was indicated as the source of this flows. Unfortunately, the regions of confidence around the mean maximum susceptibility (Fig. 7) were not all as well defined as in the previous flows perhaps reflecting the assymmetric distribution of samples 
Table 4. AMS results. Each sample has three lines corresponding to the three principal susceptibilities. The first column is the sample number, P.S. = principal susceptibility, $\mathrm{K}=$ susceptibility in SI units, Dec $=$ declination, Inc $=$ inclination. (a) Three North group flows and (b) three South group flows.

(a)

\begin{tabular}{|c|c|c|c|c|c|c|c|c|c|}
\hline Sample & P.S. & $\mathrm{K}$ & Dec & Inc & Sample & P.S. & K & Dec & Inc \\
\hline \multicolumn{2}{|c|}{ Flow N-1 } & & & & N1-14A & MAX & $1.532 \mathrm{E}-02$ & 241.0 & 52.0 \\
\hline N1-1A & MAX & $1.712 \mathrm{E}-02$ & 227.0 & 25.0 & N1-14A & INT & $1.529 \mathrm{E}-02$ & 133.0 & 13.0 \\
\hline N1-1A & INT & $1.677 \mathrm{E}-02$ & 134.0 & 6.0 & N1-14A & MIN & $1.511 \mathrm{E}-02$ & 34.0 & 35.0 \\
\hline \multirow[t]{2}{*}{ N1-1A } & MIN & $1.660 \mathrm{E}-02$ & 30.0 & 64.0 & & & & & \\
\hline & & & & & N1-14B & MAX & $1.506 \mathrm{E}-02$ & 130.0 & 7.0 \\
\hline $\mathrm{N} 1-2 \mathrm{~A}$ & MAX & $1.804 \mathrm{E}-02$ & 60.0 & 5.0 & N1-14B & INT & $1.502 \mathrm{E}-02$ & 231.0 & 57.0 \\
\hline $\mathrm{N} 1-2 \mathrm{~A}$ & INT & $1.787 \mathrm{E}-02$ & 160.0 & 63.0 & N1-14B & MIN & $1.489 \mathrm{E}-02$ & 35.0 & 32.0 \\
\hline \multirow[t]{2}{*}{ N1-2A } & MIN & $1.784 \mathrm{E}-02$ & 328.0 & 26.0 & & & & & \\
\hline & & & & & N1-15A & MAX & $1.565 \mathrm{E}-02$ & 48.0 & 25.0 \\
\hline N1-3A & MAX & $1.642 \mathrm{E}-02$ & 246.0 & 16.0 & $\mathrm{~N} 1-15 \mathrm{~A}$ & INT & $1.535 \mathrm{E}-02$ & 280.0 & 54.0 \\
\hline N1-3A & INT & $1.588 \mathrm{E}-02$ & 37.0 & 71.0 & N1-15A & $\mathrm{MIN}$ & $1.516 \mathrm{E}-02$ & 151.0 & 25.0 \\
\hline \multirow[t]{2}{*}{ N1-3A } & MIN & $1.576 \mathrm{E}-02$ & 153.0 & 8.0 & & & & & \\
\hline & & & & & N1-15B & MAX & $1.848 \mathrm{E}-02$ & 40.0 & 28.0 \\
\hline N1-3B & MAX & $1.660 \mathrm{E}-02$ & 240.0 & 18.0 & N1-15B & INT & $1.808 \mathrm{E}-02$ & 271.0 & 50.0 \\
\hline N1-3B & INT & $1.600 \mathrm{E}-02$ & 87.0 & 70.0 & N1-15B & MIN & $1.785 \mathrm{E}-02$ & 145.0 & 26.0 \\
\hline \multirow[t]{2}{*}{ N1-3B } & $\mathrm{MIN}$ & $1.582 \mathrm{E}-02$ & 333.0 & 9.0 & & & & & \\
\hline & & & & & N1-16A & MAX & $1.885 \mathrm{E}-02$ & 83.0 & 21.0 \\
\hline N1-4A & MAX & $2.041 \mathrm{E}-02$ & 161.0 & 71.0 & N1-16A & INT & $1.834 \mathrm{E}-02$ & 175.0 & 5.0 \\
\hline N1-4A & INT & $1.991 \mathrm{E}-02$ & 57.0 & 5.0 & N1-16A & MIN & $1.810 \mathrm{E}-02$ & 278.0 & 68.0 \\
\hline \multirow[t]{2}{*}{ N1-4A } & MIN & $1.962 \mathrm{E}-02$ & 325.0 & 19.0 & & & & & \\
\hline & & & & & N1-17A & MAX & $1.880 \mathrm{E}-02$ & 251.0 & 73.0 \\
\hline $\mathrm{N} 1-6 \mathrm{~A}$ & MAX & $1.924 \mathrm{E}-02$ & 43.0 & 42.0 & N1-17A & INT & $1.838 \mathrm{E}-02$ & 89.0 & 17.0 \\
\hline N1-6A & INT & $1.914 \mathrm{E}-02$ & 149.0 & 17.0 & N1-17A & MIN & $1.771 \mathrm{E}-02$ & 357.0 & 5.0 \\
\hline \multirow[t]{2}{*}{ N1-6A } & MIN & $1.889 \mathrm{E}-02$ & 255.0 & 44.0 & & & & & \\
\hline & & & & & $\mathrm{N} 1-17 \mathrm{~B}$ & MAX & $2.182 \mathrm{E}-02$ & 265.0 & 72.0 \\
\hline N1-7A & MAX & $1.991 \mathrm{E}-02$ & 95.0 & 25.0 & N1-17B & INT & $2.140 \mathrm{E}-02$ & 99.0 & 17.0 \\
\hline N1-7A & INT & $1.973 \mathrm{E}-02$ & 356.0 & 20.0 & N1-17B & MIN & $2.038 \mathrm{E}-02$ & 8.0 & 4.0 \\
\hline \multirow[t]{2}{*}{ N1-7A } & MIN & $1.949 \mathrm{E}-02$ & 231.0 & 58.0 & & & & & \\
\hline & & & & & N1-18A & MAX & $1.365 \mathrm{E}-02$ & 186.0 & 88.0 \\
\hline N1-8A & MAX & $1.671 \mathrm{E}-02$ & 63.0 & 4.0 & N1-18A & INT & $1.322 \mathrm{E}-02$ & 73.0 & 1.0 \\
\hline N1-8A & INT & $1.470 \mathrm{E}-02$ & 159.0 & 58.0 & N1-18A & MIN & $1.315 \mathrm{E}-02$ & 343.0 & 2.0 \\
\hline \multirow[t]{2}{*}{ N1-8A } & MIN & $1: 449 \mathrm{E}-02$ & 331.0 & 32.0 & & & & & \\
\hline & & & & & N1-18B & MAX & $1.331 \mathrm{E}-02$ & 127.0 & 83.0 \\
\hline N1-9A & MAX & $1.931 \mathrm{E}-02$ & 59.0 & 17.0 & N1-18B & INT & $1.283 \mathrm{E}-02$ & 243.0 & 3.0 \\
\hline N1-9A & INT & $1.756 \mathrm{E}-02$ & 167.0 & 46.0 & N1-18B & MIN & $1.280 \mathrm{E}-02$ & 333.0 & 6.0 \\
\hline \multirow[t]{2}{*}{ N1-9A } & MIN & $1.711 \mathrm{E}-02$ & 315.0 & 39.0 & & & & & \\
\hline & & & & & N1-19A & MAX & $1.595 \mathrm{E}-02$ & 1.0 & 79.0 \\
\hline N1-10A & MAX & $1.835 \mathrm{E}-02$ & 70.0 & 30.0 & N1-19A & INT & $1.516 \mathrm{E}-02$ & 145.0 & 9.0 \\
\hline $\mathrm{N} 1-10 \mathrm{~A}$ & INT & $1.790 \mathrm{E}-02$ & 217.0 & 55.0 & N1-19A & MIN & $1.509 \mathrm{E}-02$ & 236.0 & 6.0 \\
\hline \multirow{2}{*}{ N1-10A } & MIN & $1.751 \mathrm{E}-02$ & 330.0 & 15.0 & & & & & \\
\hline & & & & & N1-20A & MAX & $1.650 \mathrm{E}-02$ & 347.0 & 28.0 \\
\hline N1-10B & MAX & $1.809 \mathrm{E}-02$ & 72.0 & 34.0 & N1-20A & INT & $1.585 \mathrm{E}-02$ & 83.0 & 11.0 \\
\hline N1-10B & INT & $1.762 \mathrm{E}-02$ & 226.0 & 53.0 & N1-20A & MIN & $1.565 \mathrm{E}-02$ & 192.0 & 59.0 \\
\hline \multirow[t]{2}{*}{ N1-10B } & MIN & $1.720 \mathrm{E}-02$ & 333.0 & 12.0 & & & & & \\
\hline & & & & & N1-21A & MAX & $2.481 \mathrm{E}-02$ & 35.0 & 1.0 \\
\hline $\mathrm{N} 1-12 \mathrm{~A}$ & MAX & $2.068 \mathrm{E}-02$ & 246.0 & 6.0 & $\mathrm{~N} 1-21 \mathrm{~A}$ & INT & $2.472 \mathrm{E}-02$ & 305.0 & 0.0 \\
\hline $\mathrm{N} 1-12 \mathrm{~A}$ & INT & $2.043 \mathrm{E}-02$ & 336.0 & 2.0 & N1-21A & MIN & $2.395 \mathrm{E}-02$ & 186.0 & 89.0 \\
\hline \multirow[t]{2}{*}{$\mathrm{N} 1-12 \mathrm{~A}$} & MIN & $2.018 \mathrm{E}-02$ & 85.0 & 83.0 & & & & & \\
\hline & & & & & N1-23A & MAX & $2.261 \mathrm{E}-02$ & 30.0 & 21.0 \\
\hline N1-13B & MAX & $1.488 \mathrm{E}-02$ & 274.0 & 10.0 & N1-23A & INT & $2.216 \mathrm{E}-02$ & 288.0 & 29.0 \\
\hline N1-13B & INT & $1.476 \mathrm{E}-02$ & 177.0 & 34.0 & N1-23A & MIN & $2.207 \mathrm{E}-02$ & 150.0 & 53.0 \\
\hline
\end{tabular}


Table 4. (continued).

\begin{tabular}{|c|c|c|c|c|c|c|c|c|c|}
\hline Sample & P.S. & $\mathrm{K}$ & Dec & Inc & Sample & P.S. & K & Dec & Inc \\
\hline N1-24A & MAX & $2.175 \mathrm{E}-02$ & 50.0 & 23.0 & Flow N-2 & & & & \\
\hline $\mathrm{N} 1-24 \mathrm{~A}$ & INT & $2.151 \mathrm{E}-02$ & 308.0 & 26.0 & $\mathrm{~N} 2-1 \mathrm{~A}$ & MAX & $1.941 \mathrm{E}-02$ & 34.0 & 46.0 \\
\hline \multirow[t]{2}{*}{$\mathrm{N} 1-24 \mathrm{~A}$} & MIN & $2.136 \mathrm{E}-02$ & 175.0 & 54.0 & $\mathrm{~N} 2-1 \mathrm{~A}$ & INT & $1.908 \mathrm{E}-02$ & 259.0 & 35.0 \\
\hline & & & & & N2-1A & MIN & $1.866 \mathrm{E}-02$ & 151.0 & 24.0 \\
\hline $\mathrm{N} 1-25 \mathrm{~B}$ & MAX & $1.679 \mathrm{E}-02$ & 72.0 & 45.0 & & & & & \\
\hline N1-25B & INT & $1.671 \mathrm{E}-02$ & 297.0 & 36.0 & $\mathrm{~N} 2-2 \mathrm{~A}$ & MAX & $3.662 \mathrm{E}-02$ & 53.0 & 0.0 \\
\hline \multirow[t]{2}{*}{$\mathrm{N} 1-25 \mathrm{~B}$} & MIN & $1.657 \mathrm{E}-02$ & 188.0 & 24.0 & $\mathrm{~N} 2-2 \mathrm{~A}$ & INT & $3.071 \mathrm{E}-02$ & 143.0 & 11.0 \\
\hline & & & & & $\mathrm{N} 2-2 \mathrm{~A}$ & MIN & $3.010 \mathrm{E}-02$ & 322.0 & 79.0 \\
\hline $\mathrm{N} 1-26 \mathrm{~A}$ & MAX & $1.674 \mathrm{E}-02$ & 64.0 & 36.0 & & & & & \\
\hline $\mathrm{N} 1-26 \mathrm{~A}$ & INT & $1.668 \mathrm{E}-02$ & 157.0 & 3.0 & $\mathrm{~N} 2-5 \mathrm{~A}$ & MAX & $2.680 \mathrm{E}-02$ & 73.0 & 11.0 \\
\hline \multirow[t]{2}{*}{$\mathrm{N} 1-26 \mathrm{~A}$} & MIN & $1.661 \mathrm{E}-02$ & 251.0 & 54.0 & $\mathrm{~N} 2-5 \mathrm{~A}$ & INT & $2.560 \mathrm{E}-02$ & 174.0 & 43.0 \\
\hline & & & & & $\mathrm{N} 2-5 \mathrm{~A}$ & MIN & $2.540 \mathrm{E}-02$ & 332.0 & 45.0 \\
\hline N1-26B & MAX & $1.446 \mathrm{E}-02$ & 15.0 & 54.0 & & & & & \\
\hline N1-26B & INT & $1.441 \mathrm{E}-02$ & 128.0 & 15.0 & $\mathrm{~N} 2-6 \mathrm{~A}$ & MAX & $2.440 \mathrm{E}-02$ & 53.0 & 18.0 \\
\hline \multirow[t]{2}{*}{ N1-26B } & MIN & $1.433 \mathrm{E}-02$ & 228.0 & 31.0 & $\mathrm{~N} 2-6 \mathrm{~A}$ & INT & $2.300 \mathrm{E}-02$ & 143.0 & 1.0 \\
\hline & & & & & $\mathrm{N} 2-6 \mathrm{~A}$ & MIN & $2.260 \mathrm{E}-02$ & 236.0 & 72.0 \\
\hline N1-27A & MAX & $1.493 \mathrm{E}-02$ & 23.0 & 54.0 & & & & & \\
\hline N1-27A & INT & $1.484 \mathrm{E}-02$ & 125.0 & 8.0 & $\mathrm{~N} 2-7 \mathrm{~A}$ & MAX & $2.474 \mathrm{E}-02$ & 64.0 & 19.0 \\
\hline \multirow[t]{2}{*}{$\mathrm{N} 1-27 \mathrm{~A}$} & MIN & $1.471 \mathrm{E}-02$ & 221.0 & 35.0 & N2-7A & INT & $2.401 \mathrm{E}-02$ & 156.0 & 4.0 \\
\hline & & & & & $\mathrm{N} 2-7 \mathrm{~A}$ & MIN & $2.364 \mathrm{E}-02$ & 257.0 & 70.0 \\
\hline N1-28A & MAX & $1.547 \mathrm{E}-02$ & 45.0 & 44.0 & & & & & \\
\hline N1-28A & INT & $1.540 \mathrm{E}-02$ & 150.0 & 15.0 & N2-8A & MAX & $1.926 \mathrm{E}-02$ & 28.0 & 16.0 \\
\hline \multirow[t]{2}{*}{ N1-28A } & MIN & $1.527 \mathrm{E}-02$ & 254.0 & 42.0 & $\mathrm{~N} 2-8 \mathrm{~A}$ & INT & $1.875 \mathrm{E}-02$ & 119.0 & 5.0 \\
\hline & & & & & $\mathrm{N} 2-8 \mathrm{~A}$ & MIN & $1.863 \mathrm{E}-02$ & 227.0 & 73.0 \\
\hline $\mathrm{N} 1-29 \mathrm{~A}$ & MAX & $2.133 \mathrm{E}-02$ & 85.0 & 68.0 & & & & & \\
\hline $\mathrm{N} 1-29 \mathrm{~A}$ & INT & $2.113 \mathrm{E}-02$ & 352.0 & 1.0 & Flow N-4 & & & & \\
\hline \multirow[t]{2}{*}{ N1-29A } & MIN & $2.087 \mathrm{E}-02$ & 261.0 & 22.0 & N4-1A & MAX & $2.388 \mathrm{E}-02$ & 198.0 & 4.0 \\
\hline & & & & & N4-1A & INT & $2.348 \mathrm{E}-02$ & 101.0 & 57.0 \\
\hline N1-29B & MAX & $2.187 \mathrm{E}-02$ & 112.0 & 68.0 & N4-1A & MIN & $2.293 \mathrm{E}-02$ & 291.0 & 32.0 \\
\hline N1-29B & INT & $2.160 \mathrm{E}-02$ & 358.0 & 9.0 & & & & & \\
\hline \multirow[t]{2}{*}{ N1-29B } & MIN & $2.133 \mathrm{E}-02$ & 265.0 & 20.0 & $\mathrm{~N} 4-2 \mathrm{~A}$ & MAX & $3.381 \mathrm{E}-02$ & 45.0 & 21.0 \\
\hline & & & & & N4-2A & INT & $3.335 \mathrm{E}-02$ & 214.0 & 68.0 \\
\hline $\mathrm{N} 1-30 \mathrm{~A}$ & MAX & $1.584 \mathrm{E}-02$ & 93.0 & 57.0 & N4-2A & MIN & $3.287 \mathrm{E}-02$ & 313.0 & 4.0 \\
\hline $\mathrm{N} 1-30 \mathrm{~A}$ & INT & $1.564 \mathrm{E}-02$ & 188.0 & 3.0 & & & & & \\
\hline \multirow[t]{2}{*}{$\mathrm{N} 1-30 \mathrm{~A}$} & MIN & $1.553 \mathrm{E}-02$ & 280.0 & 32.0 & N4-3A & MAX & $3.306 \mathrm{E}-02$ & 44.0 & 27.0 \\
\hline & & & & & N4-3A & INT & $3.262 \mathrm{E}-02$ & 230.0 & 63.0 \\
\hline $\mathrm{N} 1-31 \mathrm{~A}$ & MAX & $1.893 \mathrm{E}-02$ & 33.0 & 36.0 & N4-3A & MIN & $3.206 \mathrm{E}-02$ & 136.0 & 2.0 \\
\hline $\mathrm{N} 1-31 \mathrm{~A}$ & INT & $1.883 \mathrm{E}-02$ & 129.0 & 8.0 & & & & & \\
\hline \multirow[t]{2}{*}{ N1-31A } & MIN & $1.864 \mathrm{E}-02$ & 229.0 & 53.0 & N4-5A & MAX & $2.824 \mathrm{E}-02$ & 204.0 & 2.0 \\
\hline & & & & & N4-5A & INT & $2.805 \mathrm{E}-02$ & 296.0 & 47.0 \\
\hline $\mathrm{N} 1-32 \mathrm{~A}$ & MAX & $1.896 \mathrm{E}-02$ & 29.0 & 60.0 & N4-5A & MIN & $2.768 \mathrm{E}-02$ & 113.0 & 43.0 \\
\hline $\mathrm{N} 1-32 \mathrm{~A}$ & INT & $1.869 \mathrm{E}-02$ & 297.0 & 1.0 & & & & & \\
\hline \multirow[t]{2}{*}{$\mathrm{N} 1-32 \mathrm{~A}$} & MIN & $1.854 \mathrm{E}-02$ & 206.0 & 30.0 & N4-6A & MAX & $2.278 \mathrm{E}-02$ & 218.0 & 8.0 \\
\hline & & & & & N4-6A & INT & $2.248 \mathrm{E}-02$ & 318.0 & 53.0 \\
\hline N1-34A & MAX & $5.684 \mathrm{E}-02$ & 158.0 & 22.0 & N4-6A & MIN & $2.206 \mathrm{E}-02$ & 123.0 & 36.0 \\
\hline N1-34A & INT & $5.638 \mathrm{E}-02$ & 60.0 & 19.0 & & & & & \\
\hline \multirow[t]{2}{*}{ N1-34A } & MIN & $5.492 \mathrm{E}-02$ & 293.0 & 61.0 & N4-7A & MAX & $3.176 \mathrm{E}-02$ & 221.0 & 6.0 \\
\hline & & & & & N4-7A & INT & $3.034 \mathrm{E}-02$ & 317.0 & 48.0 \\
\hline $\mathrm{N} 1-37 \mathrm{~A}$ & MAX & $1.944 \mathrm{E}-02$ & 4.0 & 16.0 & N4-7A & $\mathrm{MIN}$ & $2.994 \mathrm{E}-02$ & 125.0 & 41.0 \\
\hline N1-37A & INT & $1.919 \mathrm{E}-02$ & 252.0 & 54.0 & & & & & \\
\hline \multirow[t]{2}{*}{ N1-37A } & MIN & $1.915 \mathrm{E}-02$ & 104.0 & 32.0 & N4-7B & MAX & $2.875 \mathrm{E}-02$ & 36.0 & 8.0 \\
\hline & & & & & N4-7B & INT & $2.828 \mathrm{E}-02$ & 296.0 & 51.0 \\
\hline N1-38A & MAX & $1.266 \mathrm{E}-02$ & 195.0 & 1.0 & N4-7B & MIN & $2.787 \mathrm{E}-02$ & 132.0 & 38.0 \\
\hline
\end{tabular}

$\begin{array}{llllr}\text { N1-38A } & \text { INT } & 1.253 \mathrm{E}-02 & 105.0 & 4.0 \\ \text { N1-38A } & \text { MIN } & 1.243 \mathrm{E}-02 & 300.0 & 86.0\end{array}$


Table 4. (continued).

\begin{tabular}{|c|c|c|c|c|c|c|c|c|c|}
\hline Sample & P.S. & $\mathrm{K}$ & Dec & Inc & Sample & P.S. & $\mathrm{K}$ & Dec & Inc \\
\hline N4-8A & MAX & $2.653 \mathrm{E}-02$ & 189.0 & 0.0 & N4-14A & MAX & $9.849 \mathrm{E}-03$ & 181.0 & 4.0 \\
\hline $\mathrm{N} 4-8 \mathrm{~A}$ & INT & 2.619E-02 & 279.0 & 36.0 & N4-14A & $\mathrm{INT}$ & $9.838 \mathrm{E}-03$ & 91.0 & 4.0 \\
\hline N4-8A & MIN & $2.576 \mathrm{E}-02$ & 99.0 & 54.0 & N4-14A & MIN & $9.745 \mathrm{E}-03$ & 312.0 & 84.0 \\
\hline N4-9A & MAX & $3.511 \mathrm{E}-02$ & 213.0 & 2.0 & N4-15A & MAX & $2.338 \mathrm{E}-02$ & 190.0 & 5.0 \\
\hline N4-9A & INT & $3.450 \mathrm{E}-02$ & 308.0 & 59.0 & N4-15A & INT & $2.310 \mathrm{E}-02$ & 303.0 & 78.0 \\
\hline N4-9A & MIN & $3.370 \mathrm{E}-02$ & 122.0 & 30.0 & N4-15A & MIN & $2.291 \mathrm{E}-02$ & 99.0 & 11.0 \\
\hline N4-10A & MAX & $4.233 \mathrm{E}-02$ & 257.0 & 30.0 & N4-16A & MAX & $2.402 \mathrm{E}-02$ & 86.0 & 3.0 \\
\hline $\mathrm{N} 4-10 \mathrm{~A}$ & INT & $3.475 \mathrm{E}-02$ & 11.0 & 35.0 & N4-16A & INT & $2.374 \mathrm{E}-02$ & 178.0 & 35.0 \\
\hline N4-10A & MIN & $3.340 \mathrm{E}-02$ & 137.0 & 40.0 & N4-16A & MIN & $2.337 \mathrm{E}-02$ & 351.0 & 55.0 \\
\hline N4-11A & MAX & $3.063 \mathrm{E}-02$ & 131.0 & 45.0 & N4-16BA & MAX & $4.538 \mathrm{E}-02$ & 253.0 & 51.0 \\
\hline N4-11A & INT & $3.014 \mathrm{E}-02$ & 232.0 & 11.0 & N4-16BA & INT & $4.519 \mathrm{E}-02$ & 100.0 & 36.0 \\
\hline N4-11A & MIN & $2.923 \mathrm{E}-02$ & 332.0 & 43.0 & N4-16BA & MIN & $4.434 \mathrm{E}-02$ & 1.0 & 13.0 \\
\hline N4-12A & MAX & $5.494 \mathrm{E}-03$ & 194.0 & 21.0 & N4-17A & MAX & $4.319 \mathrm{E}-02$ & 234.0 & 11.0 \\
\hline N4-12A & INT & $5.442 \mathrm{E}-03$ & 299.0 & 33.0 & N4-17A & INT & $4.254 \mathrm{E}-02$ & 327.0 & 14.0 \\
\hline N4-12A & MIN & $5.275 \mathrm{E}-03$ & 78.0 & 49.0 & N4-17A & $\mathrm{MIN}$ & $4.207 \mathrm{E}-02$ & 107.0 & 72.0 \\
\hline N4-13A & MAX & $1.784 \mathrm{E}-03$ & 43.0 & 10.0 & N4-19A & MAX & $4.635 \mathrm{E}-02$ & 77.0 & 10.0 \\
\hline N4-13A & INT & $1.750 \mathrm{E}-03$ & 143.0 & 45.0 & N4-19A & INT & $4.603 \mathrm{E}-02$ & 173.0 & 30.0 \\
\hline N4-13A & $\mathrm{MIN}$ & $1.721 \mathrm{E}-03$ & 302.0 & 43.0 & N4-19A & MIN & $4.526 \mathrm{E}-02$ & 330.0 & 58.0 \\
\hline
\end{tabular}

(b)

\begin{tabular}{|c|c|c|c|c|c|c|c|c|c|}
\hline Sample & P.S. & $\mathrm{K}$ & Dec & Inc & Sample & P.S. & $\mathrm{K}$ & Dec & Inc \\
\hline \multicolumn{5}{|c|}{ Flow S-2 } & \multicolumn{5}{|c|}{ Flow S-3 } \\
\hline S2-9A & MAX & $7.141 \mathrm{E}-03$ & 75.0 & 52.0 & S3-15A & MAX & $1.606 \mathrm{E}-02$ & 241.0 & 2.0 \\
\hline S2-9A & INT & $7.058 \mathrm{E}-03$ & 180.0 & 12.0 & S3-15A & INT & $1.585 \mathrm{E}-02$ & 332.0 & 15.0 \\
\hline S2-9A & MIN & $7.032 \mathrm{E}-03$ & 279.0 & 36.0 & S3-15A & MIN & $1.579 \mathrm{E}-02$ & 146.0 & 74.0 \\
\hline S2-10A & MAX & $1.226 \mathrm{E}-02$ & 264.0 & 8.0 & S3-17A & MAX & $2.177 \mathrm{E}-02$ & 42.0 & 16.0 \\
\hline $\mathrm{S} 2-10 \mathrm{~A}$ & INT & $1.219 \mathrm{E}-02$ & 172.0 & 16.0 & S3-17A & INT & $2.174 \mathrm{E}-02$ & 306.0 & 21.0 \\
\hline $\mathrm{S} 2-10 \mathrm{~A}$ & MIN & $1.206 \mathrm{E}-02$ & 21.0 & 72.0 & S3-17A & $\mathrm{MIN}$ & $2.170 \mathrm{E}-02$ & 167.0 & 63.0 \\
\hline S2-10B & MAX & $1.232 \mathrm{E}-02$ & 262.0 & 3.0 & S3-18A & MAX & $1.311 \mathrm{E}-02$ & 276.0 & 15.0 \\
\hline S2-10B & INT & $1.228 \mathrm{E}-02$ & 172.0 & 4.0 & S3-18A & INT & $1.307 \mathrm{E}-02$ & 14.0 & 26.0 \\
\hline S2-10B & $\mathrm{MIN}$ & $1.218 \mathrm{E}-02$ & 30.0 & 85.0 & S3-18A & MIN & $1.302 \mathrm{E}-02$ & 158.0 & 60.0 \\
\hline $\mathrm{S} 2-12 \mathrm{~A}$ & MAX & $1.739 \mathrm{E}-02$ & 210.0 & 15.0 & S3-18B & MAX & $1.216 \mathrm{E}-02$ & 6.0 & 21.0 \\
\hline $\mathrm{S} 2-12 \mathrm{~A}$ & INT & $1.720 \mathrm{E}-02$ & 114.0 & 23.0 & S3-18B & INT & $1.215 \mathrm{E}-02$ & 266.0 & 25.0 \\
\hline S2-12A & MIN & $1.691 \mathrm{E}-02$ & 330.0 & 62.0 & S3-18B & MIN & $1.208 \mathrm{E}-02$ & 131.0 & 56.0 \\
\hline $\mathrm{S} 2-13 \mathrm{~A}$ & MAX & $9.298 \mathrm{E}-03$ & 148.0 & 22.0 & S3-19A & MAX & $1.307 \mathrm{E}-02$ & 311.0 & 18.0 \\
\hline S2-13A & INT & $9.267 \mathrm{E}-03$ & 52.0 & 14.0 & S3-19A & INT & $1.305 \mathrm{E}-02$ & 52.0 & 29.0 \\
\hline $\mathrm{S} 2-13 \mathrm{~A}$ & MIN & $9.200 \mathrm{E}-03$ & 292.0 & 63.0 & S3-19A & MIN & $1.300 \mathrm{E}-02$ & 194.0 & 55.0 \\
\hline $\mathrm{S} 2-14 \mathrm{~A}$ & MAX & $1.446 \mathrm{E}-02$ & 37.0 & 26.0 & S3-19B & MAX & $1.138 \mathrm{E}-02$ & 304.0 & 17.0 \\
\hline S2-14A & INT & $1.408 \mathrm{E}-02$ & 145.0 & 32.0 & S3-19B & INT & $1.137 \mathrm{E}-02$ & 41.0 & 21.0 \\
\hline S2-14A & MIN & $1.387 \mathrm{E}-02$ & 277.0 & 46.0 & S3-19B & MIN & $1.133 \mathrm{E}-02$ & 178.0 & 62.0 \\
\hline
\end{tabular}


Table 4. (continued).

\begin{tabular}{|c|c|c|c|c|c|c|c|c|c|}
\hline Sample & P.S. & K & Dec & Inc & Sample & P.S. & K & Dec & Inc \\
\hline \multicolumn{5}{|l|}{ Flow S-4 } & S4-22A & INT & $1.980 \mathrm{E}-02$ & 282.0 & 13.0 \\
\hline S4-20A & MAX & $1.821 \mathrm{E}-02$ & 72.0 & 22.0 & S4-22A & MIN & $1.965 \mathrm{E}-02$ & 187.0 & 22.0 \\
\hline S4-20A & INT & $1.795 \mathrm{E}-02$ & 341.0 & 1.0 & & & & & \\
\hline \multirow[t]{2}{*}{$\mathrm{S} 4-20 \mathrm{~A}$} & MIN & $1.783 \mathrm{E}-02$ & 249.0 & 68.0 & S4-22B & MAX & $2.257 \mathrm{E}-02$ & 341.0 & 69.0 \\
\hline & & & & & S4-22B & INT & $2.219 \mathrm{E}-02$ & 97.0 & 9.0 \\
\hline S4-21A & MAX & $1.946 \mathrm{E}-02$ & 58.0 & 50.0 & S4-22B & MIN & $2.175 \mathrm{E}-02$ & 190.0 & 18.0 \\
\hline S4-21A & INT & $1.916 \mathrm{E}-02$ & 164.0 & 13.0 & & & & & \\
\hline \multirow[t]{2}{*}{ S4-21A } & MIN & $1.901 \mathrm{E}-02$ & 264.0 & 37.0 & S4-24A & MAX & $1.654 \mathrm{E}-02$ & 14.0 & 89.0 \\
\hline & & & & & S4-24A & $\mathbb{N N T}$ & $1.644 \mathrm{E}-02$ & 284.0 & 0.0 \\
\hline$S 4-21 B$ & MAX & $2.814 \mathrm{E}-02$ & 64.0 & 51.0 & S4-24A & MIN & $1.640 \mathrm{E}-02$ & 194.0 & 1.0 \\
\hline S4-21B & INT & $2.327 \mathrm{E}-02$ & 158.0 & 3.0 & & & & & \\
\hline \multirow[t]{2}{*}{ S4-21B } & MIN & $2.308 \mathrm{E}-02$ & 250.0 & 38.0 & S4-26B & MAX & $1.972 \mathrm{E}-02$ & 105.0 & 59.0 \\
\hline & & & & & S4-26B & INT & $1.934 \mathrm{E}-02$ & 297.0 & 31.0 \\
\hline S4-22A & MAX & $2.015 \mathrm{E}-02$ & 42.0 & 64.0 & S4-26B & MIN & $1.930 \mathrm{E}-02$ & 203.0 & 5.0 \\
\hline
\end{tabular}

as mentioned before. However, as observed from the S-4 and S-3 flows (with excellent and moderate groupings, respectively), a flow direction near an E-W trend was defined, in agreement with what was expected from their position relative to the Azufre vent, although the orientation of the ellipse of confidence around the mean maximum susceptibility in the S-3 flow leads to a large uncertitude in the azimuth of the inferred flow direction. Flow S-2 yield a poor grouping of maximum directions of susceptibility around a SW-NE direction, and although not necessarily in contradiction with the geological evidence, the poor quality of the grouping of the maximum susceptibilities made this result of a limited use.

\section{Summary}

The results of this work can be summarized as follows:

1) Combination of the directions of magnetization of the Azufre lavas with some of those previously obtained by CREER and VALENCIO (1969) yield an improved estimate of the position of the paleomagnetic pole for the Bruhnes chron using data from the Andean Cordillera. The pole coordinates are $87^{\circ} \mathrm{N}, 236^{\circ} \mathrm{E}$ with an $\alpha_{95}=12^{\circ}$.

2) By using statistical criteria it was confirmed the hypothesis of rapid extrusion of flows from the Azufre volcano and the age of the sampled groups of lavas is presumably constrained to be older than 0.4 my in the average.

3) Despite the large scatter on the directions of the principal susceptibilities of multiple samples from the same lava flow, AMS measurements can be used to estimate the flow direction of the lava at the point of sampling provided an adequate analysis technique is used to calculate the mean directions of the principal susceptibilities and a symmetric distribution of samples with respect to the middle parts of the flow is available. As a corollary, the discrimination between possible source vents can be assessed in the basis of AMS measurements.

4) The suggested criteria to determine the acceptability of the AMS results has been derived in analogy with the criteria used in paleomagnetism. However, the different orientation of the ellipse of confidence around the mean maximum susceptibility may be a definitive factor in making the final decision of wether accept or reject results from a given flow.

Partial financial support for this study was provided by DGAPA-UNAM to E. Cañón and an International Grant to E. Herrero by the University of Hawaii. Additional support to E. Herrero was provided by the Soest-HIG and by 
National Science Foundation Grants EAR-8916597, EAR-9114305 and EAR-9018270. The invaluable logistic and geologic assistance provided by all the members of the "Laboratorio de Paleomagnetismo D. Valencio" of the University of Buenos Aires, Argentina, in particular, Drs. J. F. Vilas, M. J. Orgeira and A. M. Sinito is greatly acknowledged. The assistance of Drs. M. Haller, J. Mendía, H. Ostera and the members of the group of "Gendarmeria" who accompanied us in the field, is also acknowledged. Dr. C. Constable provided us with a copy of her program that allowed calculation of the AMS regions of confidence with the bootstrap method. Finally the critical comentaries of Dr. T. Nishitani, Dr. M. Kono and specially of an anonymous reviewer greatly improved an earlier version of this manuscript. This is SOEST-HIG contribution \#3286.

\section{REFERENCES}

Bogue, S. W. and R. S. Coe, Paleomagnetic correlation of Columbia River basalt flows using secular variation, J. Geophys. Res., 86, 11883-11897, 1981.

Borradalle, G. J., Magnetic susceptibility, petrofabric and strain-A review, Tectonophysics, 156, 1-20, 1988.

Butler, R. F., Paleomagnetism: magnetic domains to geologic terranes, Blackwell Scientific Publications, Oxford, 319 pp., 1992.

CAÑóN-TAPIA, E., Palaeomagnetism of lavas from the Azufre-Planchón-Peteroa volcanic complex, Andean Cordillera, Argentina, EOS 72 Fall Meeting Suppl., 135, 1991.

Cañón-Tapia, E., G. P. L. Walker, and E. Herrero-Bervera, Magnetic properties of two flow units of Xitle volcano, Mexico: structural correlations and flow directions, EOS 74 Spring Meeting Suppl., 115, 1993a.

Cañón-Tapia, E., G. P. L. Walker, and E. Herrero-Bervera, Flow directions of lavas of Xitle volcano, México, using AMS, 1993 b (in preparation).

Constable, C. G. and L. TauXe, The bootstrap for magnetic susceptibility tensors, J. Geophys. Res., 95, 8383-8397, 1990.

Creer, K. M. and D. A. Valencio, Palaeomagnetic and rock magnetic studies on the Cenozoic basalts from western Argentina, Geophys. J. R. astr. Soc., 19, 113-146, 1969.

ELLWOoD, B. B., Estimates of flow direction for calc-alkaline welded tuffs and paleomagnetic data reliability from anisotropy of magnetic susceptibility measurements: central San Juan Mountains, southwest Colorado, Earth Planet. Sci. Lett., 59, 303$314,1982$.

ERNST, R. E. and W. R. A. BARAGar, Evidence from magnetic fabric for the flow pattern of magma in the Mackenzie giant radiating dyke swarm, Nature, 356, 511-513, 1992.

Fisher, F. R. S., Dispersion on a sphere, Proc. R. Soc., A217, 295-305, 1953.

HaRgraves, R. B., D. Johnson, and C. Y. Chan, Distribution anisotropy: the cause of AMS in igneous rocks?, Geophys. Res. Lett., 18, 2193-2196, 1991.

HeXt, G. R., The estimation of second-order tensors, with related tests and designs, Biometrika, 50, 353-373, 1963.

HroudA, F., Magnetic anisotropy of rocks and its application in geology and geophysics, Geoph. Surv., 5, 37-82, 1982.

JACKSON, M. and L. TAUXE, Anisotropy of magnetic susceptibility and remanence: developments in the characterization of tectonic, sedimentary and igneous fabric, Rev. Geophys., 29, supplement, 371-376, 1991.

JELINEK, V., Statistical processing of AMS measured on groups of specimens, Studia Geoph. Geod., 22, 50-62, 1978.

Kent, J. T., The Fisher-Bingham distribution on the sphere, J. R. Statist. Soc., 44, 71-80, 1982.

KHAN, M. A., The anisotropy of magnetic susceptibility of some igneous and metamorphic rocks, J. Geophys. Res., 67, 2873$2885,1962$.

KirschVInK, J. L., The least-squares line and plane and the analysis of palaeomagnetic data, Geophys. J. Roy. astr. Soc., 62, 699$718,1980$.

KNight, M. D. and G. P. L. WALKer, Magma flow direction in dikes of the Koolau complex, Oahu, determined from magnetic fabric studies, J. Geophys. Res., 93, 4301-4319, 1988.

KNight, M. D., G. P. L. WAlker, B. B. Ellwood, and J. F. Diehl, Stratigraphy, paleomagnetic and magnetic fabric of the Toba tuffs: constraints on the source and eruptive styles, J. Geophys. Res., 91, 10355-10382, 1986.

Kolofikova, O., Geological interpretation of magnetic properties of basalts an example of the Chribsky Les lava flow of the Velky Roudny volcano (Nizky Jesenik, Cas), Mineral. Geol., 21, 387-396, 1976 (in Czech).

LIENERT, B. R., Monte Carlo simulation of errors in the anisotropy of magnetic susceptibility: a second-rank symmetric tensor, J. Geophys. Res., 96, 19539-19544, 1991.

MCElhinny, M. W. and R. T. Merrill, Geomagnetic secular variation over the past 5 m.y., Rev. Geophys. Space Phys., 13, 687$708,1975$.

Stone, D. B., An anisotropy meter, in Methods in Palaeomagnetism, edited by D. W. Collinson, K. M. Creer and S. K. Runcorn, pp. 372-381, Elsevier, Amsterdam, 1967.

Staudigel, H., J. Gee, L. Tauxe, and R. J. Varga, Shallow intrusive directions of sheeted dikes in the Troodos ophiolite: anisotropy of magnetic susceptibility and structural data, Geology, 20, 841-844, 1992.

Symons, D. T. A., Age and flow direction from magnetic measurements on the historic Aiyansh flow, British Columbia, J. Geophys. Res., 80, 2622-2626, 1975. 
TAUXE, L., C. CONSTABLE, and L. Stokking, Use of anisotropy to determine the origin of characteristic remanence in the Siwalik red beds of northern Pakistan, J. Geophys. Res., 95, 4391-4404, 1990.

TORMEY, D. R., F. A. FREY, and L. LÓPEZ EsCOBAR, Geologic history of the active Azufre-Planchón-Peteroa volcanic center ( $35^{\circ} 15^{\prime} \mathrm{S}$, Southern Andes), with implications for the development of compositional gaps, Asoc. Geol. Argentina, Rev., 44, $420-430,1989$.

Valencio, D. A., E. Linares, and K. M. Creer, Palaeomagnetism and K-Ar ages of Cenozoic basalts from Argentina, Geophys. J. R. astr. Soc., 19, 147-164, 1970.

ZiJDERVELD, J. D. A., A.C. demagnetization of rocks: analysis of results, in Methods in Palaeomagnetism, edited by D. W. Collinson, K. M. Creer and S. K. Runcorn, pp. 254-286, Elsevier, Amsterdam, 1967. 